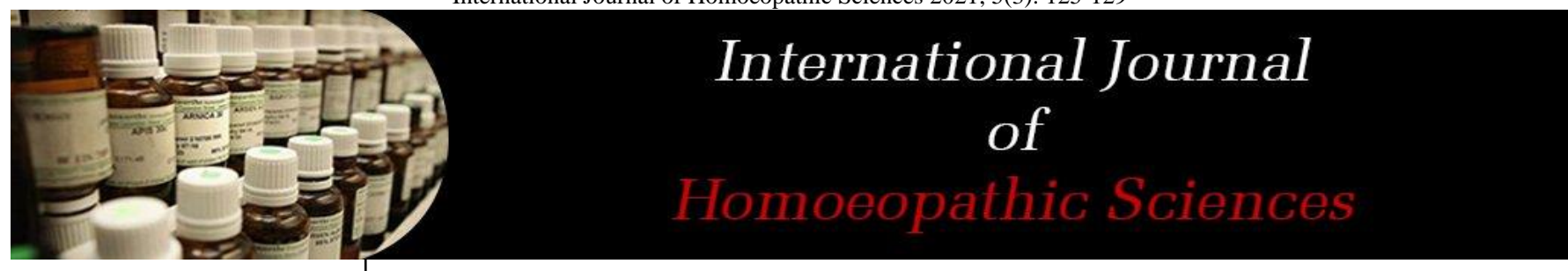

E-ISSN: $2616-4493$ P-ISSN: 2616-4485 www.homoeopathicjournal.com IJHS 2021; 5(3): 125-129

Received: 01-05-2021

Accepted: 03-06-2021

Dr. J Senthilkumar

Professor, PG Guide, Head of Department, Department of Repertory, Vinayaka Mission's Homoeopathic Medical College \& Hospital, A Constituent College of VMRF-Deemed to be University, Salem,

Tamil Nadu, India

Dr. A Sumaiyah

Assistant Professor,

Department of Human

Anatomy, Sri Sai Ram

Homoeopathy Medical College and Research Centre, Chennai,

Tamil Nadu, India
Corresponding Author:

Dr. J Senthilkumar

Professor, PG Guide, Head of Department, Department of

Repertory, Vinayaka Mission's

Homoeopathic Medical College

\& Hospital, A Constituent

College of VMRF-Deemed to

be University, Salem,

Tamil Nadu, India

\section{A clinic study on uterine fibroid and its homoeopathic management with kent repertory}

\section{Dr. J Senthilkumar and Dr. A Sumaiyah}

DOI: https://doi.org/10.33545/26164485.2021.v5.i3c.414

Abstract

Uterine fibroid is a benign i.e. a non-cancerous growth from the muscle layer of uterus \& is medically referred as fibromyomas. It is generally formed of a mixture of muscle tissues containing fibrous tissue. Myomas are frequently multiple may be found in one uterus. The tumours tend to be spherical in shape $\&$ surrounded by pseudocapsule which consists of compressed normal uterine wall.

Uterine fibroid tumors are the most common, non-cancerous pelvic masses that women experience. They arise from the muscular layer of the uterus, the myometrium ${ }^{[1]}$.

Keywords: uterine fibroid, homoeopathic management, kent repertory

\section{Introduction \\ Incidence}

It has been estimated that atleast 20 percent of ladies at 30 years old have fibroid in their bellies wombs. Fortunately, most of them remain asymptomatic. The occurrence of indicative fibroid in clinic outpatient is around 3 percent. A high incidence of 10 per cent prevails in England. In coloured races, the incidence is even higher. These are more common in nulliparous or in those having one child infertility. The prevalence is highest between $35-$ 45 years $^{[2]}$.

Negroes get fibroids multiple times more than whites. Around one - tenth of all gynecological patients in England experience the ill effects of fibroids ${ }^{[3]}$.

Uterine leiomyomas occur in $20 \%$ to $25 \%$ of women of reproductive age and reportedly affect three times as many black women as white women. The tumors become malignant (leiomyosarcoma) in only $0.1 \%$ or less of patients ${ }^{[4]}$.

\section{Symptoms}

A little more than $50 \%$ of the patients with leiomyoma have no complaints, and the diagnosis is made during a routine gynaecological examination.

\section{Physical Signs}

Anaemia, Abdominal lump, Bimanual examination will be reveal an enlarged uterus, regular or bossy depending upon the number size of the tumour ${ }^{[5]}$.

\section{Menstrual complaints}

Menorrhagia: Excessive menstrual flow may be associated with prolonged menstrual phase or normal duration with heavy flow.it is commoner and heavier with submucous tumours and unlikely to occur in subserous tumours. It occurs due to (i) increased uterine vascularity, (ii) increased endometrial surface area, (iii) endometrial hyperplasia, (iv) impaired uterine contractions due to myometrial distortion in intramural tumours, and (v) in some cases due to anovulatory cycles.

Polymennorrhoea: It is difficult to explain shorter menstrual cycles in patients with leiomyoma as the ovarian cycle is under the control of pituitary ovarian axis.

Metorrhagia: This occurs in patients with pedunculated submucous leiomyomatous polyp protruding through the cervix or in the vagina due to infection and ulceration of the dependent endometrial lining. Metrorrhagia is always a frightening symptom on account of its association with malignancy of the cervix and endometrium. 
Dysmennorrhoea: Spasmodic dysmennorrhoea occurs due to hypertonic / incoordinate uterine contractions in submucous and intramural tumours. Congestive dysmennorrhoea occurs due to vascular congestion and is aggravated by coexisting pathology like endometriosis or pelvic inflammatory disease.

\section{Pain}

A dull or dragging pain in the hypogastrium or lumbosacral region is complained by patients with large tumours. Acute pain occurs in association with red degeneration, torsion or infection and abcess formation.

\section{Infertility}

It is difficult to state in what percentage of patients leiomyoma per se can cause infertility. When all other factors of infertility both in the male and female are excluded, pregnancy rate following myomectomy is reported from 20 to $50 \%$ and the abortion rate is also increased. Very often there are other factors like pelvic inflammatory disease, anovulation and endometriosis which also contribute to infertility. Submucus tumours may cause failure of nidation of fertilized ovum. Gross distortion of the uterine cavity by intramural tumours and bilateral tubal occlusion by cornual tumours may hinder sperm ascent into the fallopian tubes.

\section{Problems during pregnancy}

A fairly large number of women with uterine leiomyoma not only conceive but also have a normal course of pregnancy, labor and puerperium. These tumours which increase substantially in size during pregnancy also regress after pregnancy. However the incidence of abortions and preterm delivery are increased as also the incidence of incoordinate uterine action in labour. Cervical tumours can cause obstructed labour. The most dreaded complication during labour are atonic postpartum haemorrhage and acute inversion of uterus ${ }^{[6]}$.

\section{Pressure symptoms}

A fibroid has usually to attain the size of a 14-week pregnancy or more before a woman is conscious of swelling of the abdomen or of the presence of a hard tumour. Smaller ones can cause a sensation of weight in the pelvis. The fibroids in the posterior wall may be impacted in the pelvis producing constipation, dysuria or even retention ofurine ${ }^{[2]}$.

\section{Aim \& Objectives of The Study}

To study the efficacy of Homoeopathic medicine in the modulation of Uterine Fibroid by using Kent repertory.

\section{Materials and Methods \\ Source of the Data}

The Subjects will be collected from the IPD,OPD\& Peripheral Health Centres and Rural Medical Camps conducted by Vinayaka Mission's Homoeopathic Medical College \& Hospital, Salem.

\section{Samples}

- Purposive sampling done as per inclusion and exclusion criteria.

- Sample size will be minimum 30 in number.

\section{Method of Collection of Data Inclusion Criteria}

Patients with fibroid uterus and having the symptoms such as heavy menstrual bleeding, menorrhagia, abdominal mass, dysmennorrhoea, infertility, recurrent miscarriage, intermenstrual bleeding, pelvic pressure or pain, frequent urination, difficulty emptying the bladder and backache or leg pain will be selected for the study.

\section{Exclusion Criteria}

Patients with uterine carcinoma, pelvic inflammatory disease, congenital diseases, major systemic illnesses and patients who have undergone or are undergoing Hormone Replacement Therapy and those who are taking contraceptive pills.

\section{Treatment Plan}

The patients were assessed, analysed and evaluated according to Dr. J.T. Kent's method.

Repertorization was done using Kent's Repertory. Miasmatic interpretation was done by using the presenting complaints, past history, family history, mental and physical generals. Mental generals, physical generals and characteristic particulars were considered for the selection of the remedy.

Criteria for follow up were mental generals, physical generals and characteristic particulars.

\section{Observation and Results}

This study was conducted at Vinayaka Mission's Homoeopathic Medical College and Hospital, Salem. Thirty patients were selected from the OPD, IPD and the peripheral centres maintained by the hospital. All the cases were treated with the homoeopathic remedies and followed for a period of 12 months. Various data from the patients were analysed and given below.

Table 1: Age Wise Distribution of Uterine Myoma

\begin{tabular}{|c|c|c|c|}
\hline S. No. & Age Groups (in years) & No. of Patients & Percentage \\
\hline 1. & $20-30$ & 4 & $13.3 \%$ \\
\hline 2. & $31-40$ & 24 & $80 \%$ \\
\hline 3. & $41-50$ & 2 & $6.7 \%$ \\
\hline & Total & 30 & $100 \%$ \\
\hline
\end{tabular}

Table shows, out of 30 cases selected for the study, maximum prevalence of uterine myoma 24 cases $(80 \%)$ were seen in the age group above $31-40$ years.

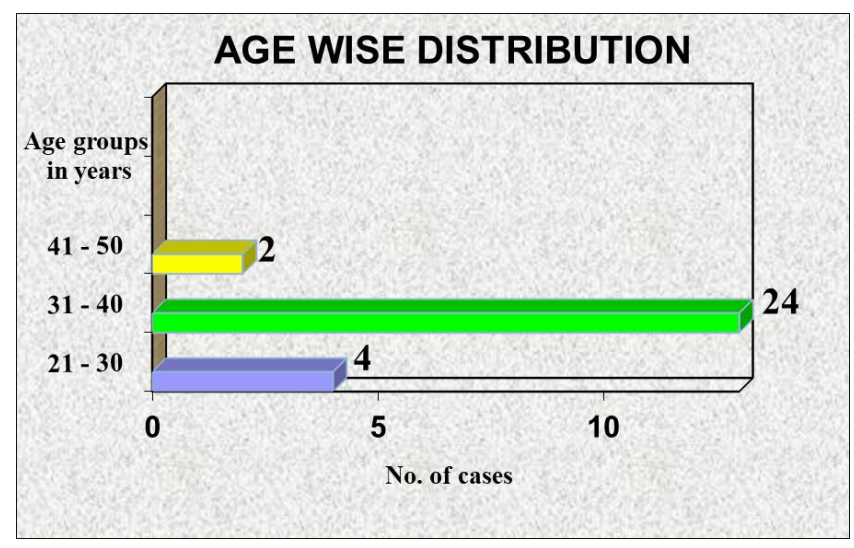

Fig 1: Bar - Diagrammatic Representations of Age Wise Distribution of Uterine Myoma 
Table 2: Distribution of Occupation.

\begin{tabular}{|c|c|c|c|}
\hline S. No. & Occupation & No. of Cases & Percentage \\
\hline 1 & Home makers & 28 & $93.3 \%$ \\
\hline 2 & Teacher & 2 & $6.7 \%$ \\
\hline & Total & 30 & $100 \%$ \\
\hline
\end{tabular}

Table shows, most of the patients were homemakers (93.3\%), teachers (6.7\%), were significantly involved.

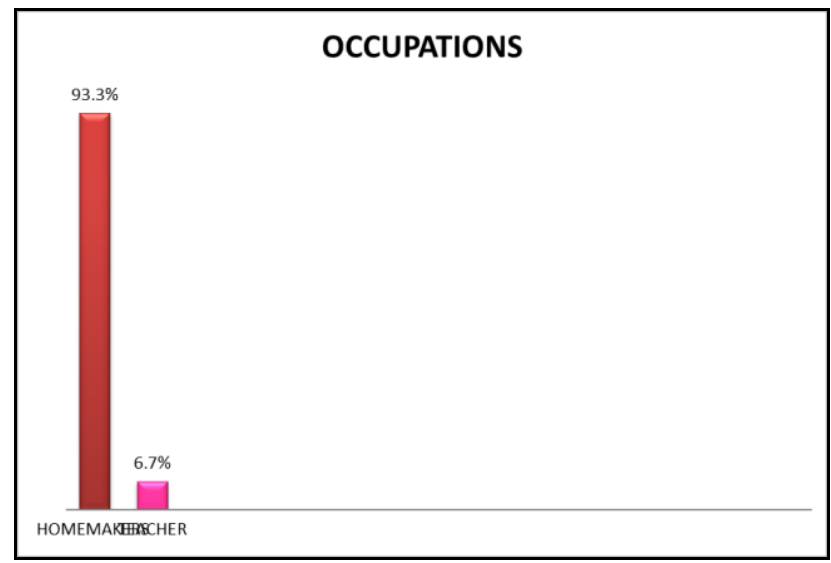

Fig 2: Bar - Diagrammatic Representation of Distribution of Occupations

Table 3: Distribution of Presenting Complaints of Uterine Myoma

\begin{tabular}{|c|c|c|c|}
\hline S. No. & Presenting complaints & No. of cases & Percentage \\
\hline 1 & Profuse menses with pain & 15 & $50 \%$ \\
\hline 2 & Pain \& profuse menses, vaginal discharge & 4 & $13.4 \%$ \\
\hline 3 & Pain in abdomen. Profuse menses, with nausea \& vomiting. & 2 & $6.7 \%$ \\
\hline 4 & Protracted menses with weakness & 2 & $6.7 \%$ \\
\hline 5 & Profuse menses with weakness & 2 & $6.7 \%$ \\
\hline 6 & pains in lower abdomen & 1 & $3.3 \%$ \\
\hline 7 & Amenorrhoea & 1 & $3.3 \%$ \\
\hline 8 & Profuse menses, vaginal discharge & 1 & $3.3 \%$ \\
\hline 9 & Profuse menses & 1 & $3.3 \%$ \\
\hline 10 & Irregular menses. Abdomen pain. Absence of menses. & $3.3 \%$ \\
\hline & Total & 30 & $100 \%$ \\
\hline
\end{tabular}

Table shows that pain with profuse menses with pain (50\%) and Pain with profuse menses and vaginal discharge $(13.4 \%)$, Pain with profuse menses, nausea and vomiting $(6.7 \%)$, protracted menses with weakness $(6.7 \%)$ profuse menses with weakness (6.7\%) and pain in abdomen, amenorrhea, irregular menses, are the most common presenting symptoms seen in uterine myoma.

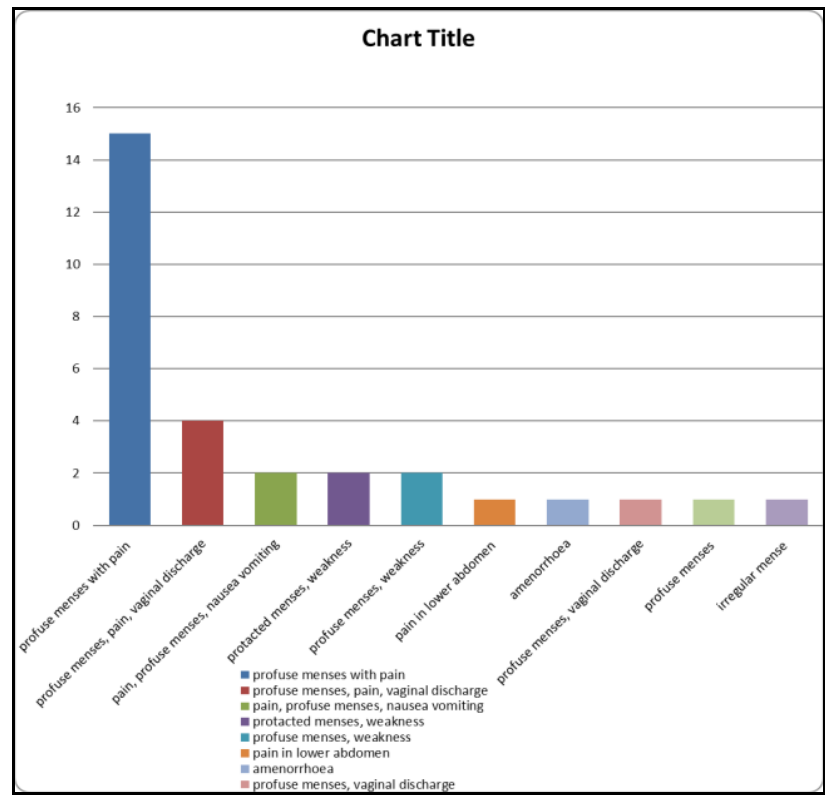

Fig 3: Column - Diagrammatic Representation of Distribution of Signs and Symptoms of Uterine Myoma. 
Table 4: Distributions of Patients Based on Fundamental Miasm.

\begin{tabular}{|c|c|c|c|}
\hline S. No & Fundamental miasm & No. of cases & Percentage \\
\hline 1 & Psora & 16 & $53.3 \%$ \\
\hline 2 & Sycosis & 1 & $3.3 \%$ \\
\hline 3 & Psoro sycotic & 7 & $23.4 \%$ \\
\hline 4 & Psoro syphilitic & 6 & $20 \%$ \\
\hline & Total & 30 & $100 \%$ \\
\hline
\end{tabular}

Table shows 16 cases $(53.3 \%)$ have psora as fundamental miasm. 1 cases $(3.3 \%)$ have sycosis as fundamental miasm. 7 cases $(23.4 \%)$ have Psorosycotic as fundamental miasm. 6 cases $(20 \%)$ have psoro syphilitic as fundamental miasm.

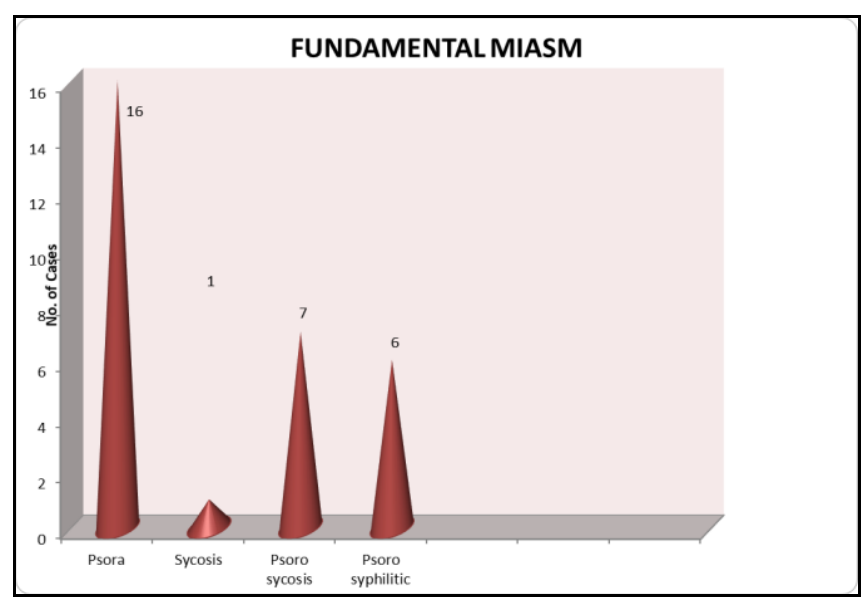

Fig 4: Column - Diagrammatic Representation of Distribution Ofpatients Based on Fundamental Miasm

Table 5: Distribution of Patients Based on Dominant Miasm

\begin{tabular}{|c|c|c|c|}
\hline S. No. & Dominant miasm & No. of cases & Percentage \\
\hline 1 & Psora & 3 & $10 \%$ \\
\hline 2 & Sycosis & 15 & $50 \%$ \\
\hline 3 & Psoro Sycotic & 10 & $33.3 \%$ \\
\hline 4 & Psoro Syphilis & 2 & $6.7 \%$ \\
\hline & Total & 30 & $100 \%$ \\
\hline
\end{tabular}

Table shows 3 cases (10\%) have Psora as dominant miasm. 15 cases $(50 \%)$ have Sycotic as dominant miasm. 10 cases (33.3\%) have Psoro sycotic as dominant miasm. 2 cases $(6.7 \%)$ have Psorosyphilitic as dominant miasm.

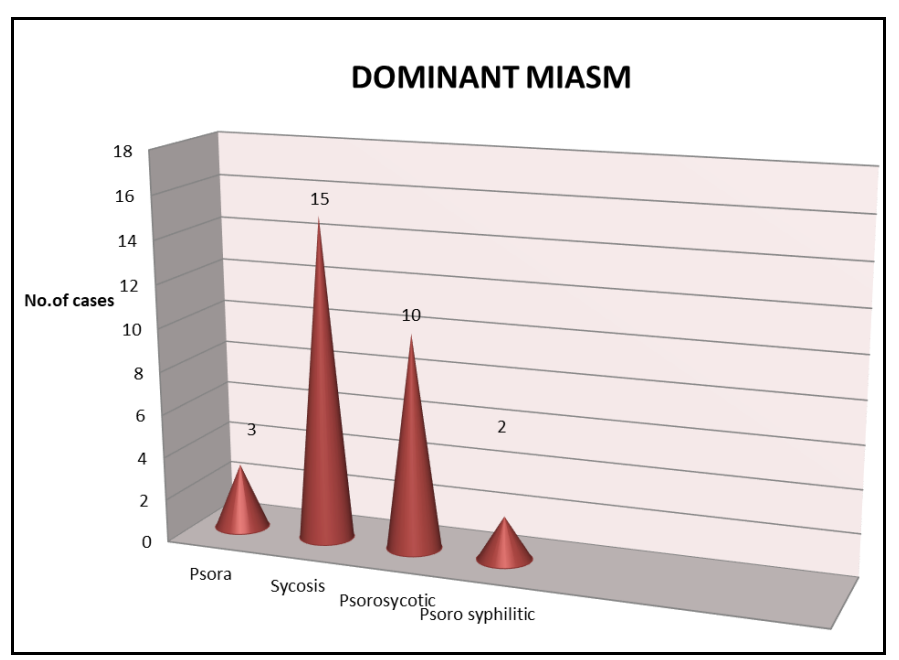

Fig 5: Column - Diagrammatic Representation of Distribution of Patients Based on Dominant Miasm

Table 6: Distribution of Patients Based on Medicine Prescription.

\begin{tabular}{|c|c|c|c|}
\hline S. No & Constitutional remedy & No. of Cases & Percentage \\
\hline 1 & Sepia & 5 & $16.7 \%$ \\
\hline 2 & Calcarea carbonicum & 4 & $13.3 \%$ \\
\hline 3 & Kali carb & 3 & $10 \%$ \\
\hline 4 & Nux vomica & 3 & $10 \%$ \\
\hline 5 & Pulsatilla & 3 & $10 \%$ \\
\hline 6 & Belladonna & 2 & $6.7 \%$ \\
\hline 7 & Sulphur & 2 & $6.7 \%$ \\
\hline 8 & Lycopodium & 1 & $3.3 \%$ \\
\hline 9 & Natrum Muriaticum & 1 & $3.3 \%$ \\
\hline 10 & Arsenicum album & 1 & $3.3 \%$ \\
\hline 11 & Phosphorus & 1 & $3.3 \%$ \\
\hline 12 & Ferrum met & 1 & $3.3 \%$ \\
\hline 13 & Cocculus indicus & 1 & $3.3 \%$ \\
\hline 14 & Ignatia & 1 & $3.3 \%$ \\
\hline 15 & Cinchona officinalis & 1 & $3.3 \%$ \\
\hline & Total & 30 & $100 \%$ \\
\hline
\end{tabular}

Table shows that Sepia (16.7\%) and Calcarea carb (13.3\%) were frequently indicated as constitutional remedies for Uterine myoma. Next to this Kali carb, nux vom, Pulsatilla, Belladonna, Sulphur is indicated.

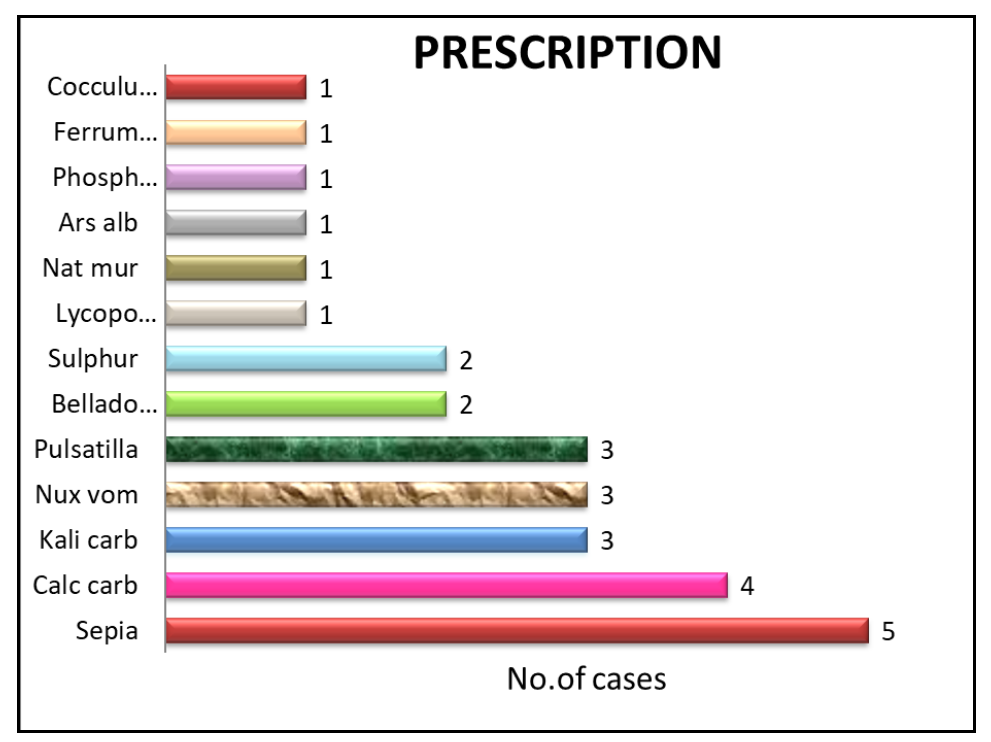

Fig 6: Bar - Diagrammatic Representation of Distribution of Prescribed Remedies In This Study 
Table 7: Distribution of Results of Homoeopathic Treatment of Uterine Myoma

\begin{tabular}{|l|c|c|c|}
\hline S.no & Result & No. of patients & Percentage \\
\hline 1. & Marked improvement & 18 & $60 \%$ \\
\hline 2. & Moderate improvement & 8 & $26.7 \%$ \\
\hline 3. & No improvement & 4 & $13.3 \%$ \\
\hline & Total & 30 & $100 \%$ \\
\hline
\end{tabular}

Table shows, out of 30 cases, 18 cases $(60 \%)$ were marked improvement and 8 cases $(26.7 \%)$ had shown moderate improvement, 4 cases $(13.3 \%)$ has no improvement.

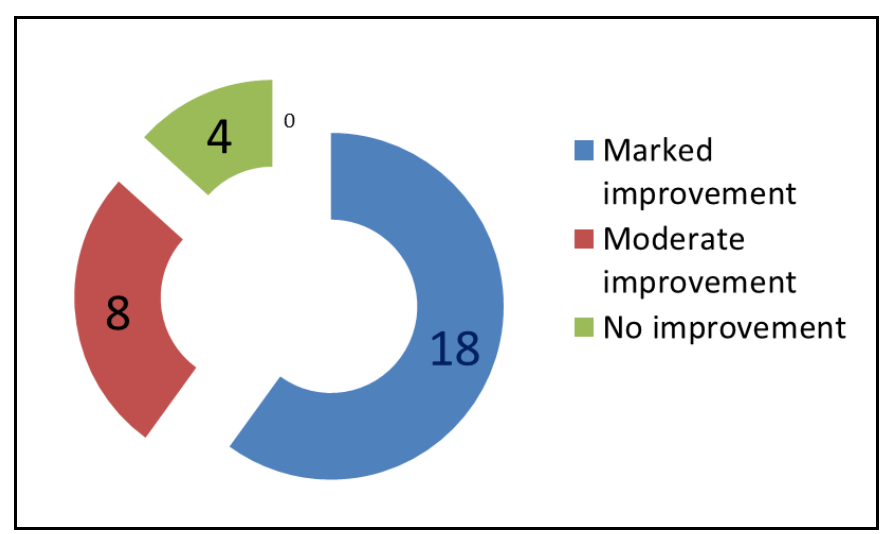

Fig 7: Doughnut - Diagrammatic Representation of Distribution of Results of Homoeopathic Treatment in This Study

\section{Summary and Conclusion}

Homoeopathic system of medicine with its unique principle and with its individualistic approach closely approximates with the modern concepts of existing medical science. Homoeopathy with its time honored clinical results has shown its efficacy in various clinical conditions demolished the speculative concept of this systems role confined to certain group of clinical conditions. Such was the case for Uterine Myoma. Thus it is imperative for any Homoeopath to have a deeper acquaintance with the tools of Homoeopathic materia medica so that their therapeutic value over various conditions could be ascertained and we could make better use of them.

\section{References}

1. www.homeomiracles.com/index/female/femalearticle/u terinefibroid/fibroids.htm. 4/4/10.

2. Dutta DC. Textbook of Gynaecology, II Edition, New Central Book Agency Pvt. Ltd 1994,

3. Dawn CS. Textbook of Gynaecology, Fully revised \& enlarged X Edition, Dawn Books 1991,

4. Padubidri VG, Shirish N. Daftary, Shaw's Textbook of Gynaecology, XIII Edition, Elsevier, a division of Reed.

5. Epidermology of Uterine Leiomyomata Clinical Obstetric Gynaecology 2001.

6. Kamal Buckshee, Principles \& Practice of Obstetrics \& Gynaecology for Post Graduates, I Edition, revised, reprint, Jaypee Brothers 1997,

7. Kent JT. Repertory of Homoeopathic Materia Medica, Enriched Indian Edition, B. Jain Publishers (P) Ltd. 2014.

8. Kothari CR. Research Methodology, Reprint Edition New age international (P) Ltd 2008.

9. Berkeley Squire, Repertory of Homoeopathic Nosodes \& Sarcodes, V Impression, B. Jain Publishers Pvt Ltd.
2015.

10. Roberts HA, Annie MD, Wilson C. Timothy Field Allen The Principles \& Practicability of Boenninghausen's Therapeutic Pocket Book, I Indian Edition, 2014, Indian Books \& Peiodicals Publishers.

11. Minton. Uterine Therapeutics - Materia Medica \& Repertory, Reprint Edition B.Jain Publishers (P) Ltd. 1999.

12. Cowperthwaite, Textbook of Gynaecology designed for the Student \& General Practitioner, Reprint edition, B. Jain Publishers Pvt. Ltd 1992.

13. Tindall VR. Jeffcoate's Principle of Gynaecology, V Edition, Butterworth - Heinemann Ltd 1987.

14. www.njhonline.com/2003/may-jun-vol5no3/mixedbag/uterine-fibroids-study4shtml. 13/09/08.

15. Dr. Nidhi Luthra, Homoeopathy for All 2003;VI:47.

16. Sir Norman Jeffcott, Principle of Gynaecology, IV Edition, 1982, Butter Worth Scientific 